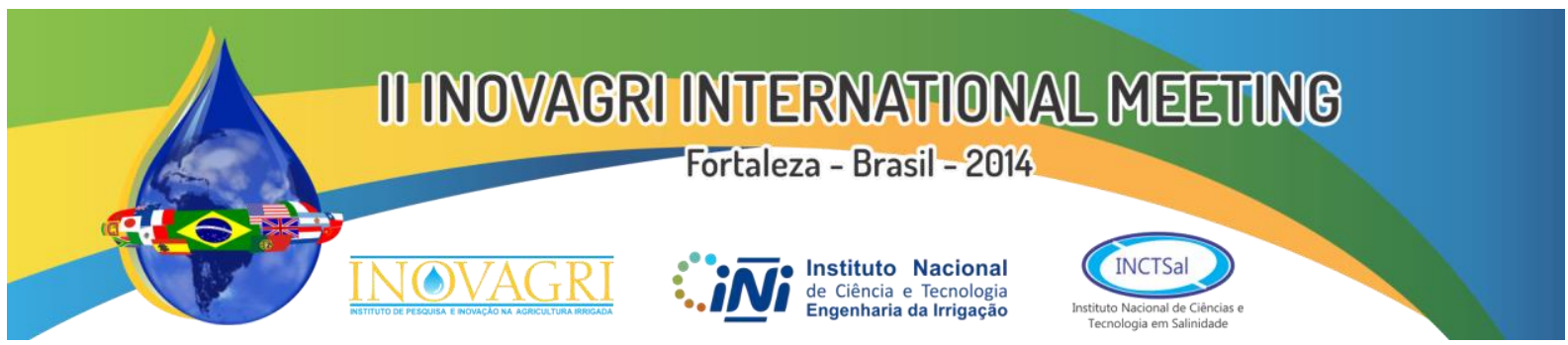

http://dx.doi.org/10.12702/ii.inovagri.2014-a108

\title{
RENDIMENTO E EFICIÊNCIA DE USO DA ÁGUA DE CULTIVARES DE ALGODOEIRO HERBÁCEO SOB DIFERENTES LÂMINAS DE IRRIGAÇÃO
}

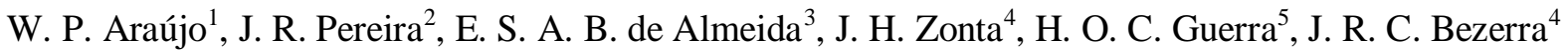

RESUMO: Estudou-se o rendimento e a eficiência de uso da água de cultivares de algodoeiro herbáceo sob diferentes lâminas de irrigação, em experimento conduzido no Campo Experimental da Embrapa Algodão, no município de Barbalha, CE. Foi utilizado o delineamento experimental em blocos casualizados, com 4 repetições, totalizando 60 subparcelas dispostas em faixas, em combinação fatorial $3 \mathrm{x}$ 5 de três cultivares de algodoeiro herbáceo ((BRS 286 (C1); BRS Aroeira (C2) e BRS Araripe (C3)) e cinco lâminas de irrigação, 260,93 (L1), 418,93 (L2), 514,21 (L3), 711,81 (L4) e 894,68 (L5) mm, correspondente a $36,58,72,100$ e $126 \%$ da ETc. O algodoeiro foi plantado em fileiras simples no espaçamento de $1,00 \times 0,20 \mathrm{~m}$, com áreas por parcela de $12 \times 15\left(180 \mathrm{~m}^{2}\right)$, sendo que a subparcela foi de 12 x $3 \mathrm{~m}\left(36 \mathrm{~m}^{2}\right)$, com área útil de $6 \mathrm{~m}^{2}$ e total experimental de $2160 \mathrm{~m}^{2}$. O volume de reposição de água em cada evento de irrigação foi calculada em função da segunda faixa ( 3 a $6 \mathrm{~m}$ da linha central de aspersores), denominada de lâmina de controle, determinada pela evapotranspiração da cultura $\left(\mathrm{ET}_{\mathrm{c}}\right)$, estimada por Penman-Monteith, multiplicada pelos coeficientes da cultura do algodão Kc nas diferentes fases fenológicas $\left(\mathrm{ETc}=\mathrm{ET}_{0} \mathrm{x} \mathrm{Kc}\right)$. O rendimento das cultivares foi afetado pelas lâminas de irrigação aplicadas e que a as cultivares BRS Araripe e BRS 286 apresentaram crescentes rendimentos com o aumento da lâmina de irrigação, destacando-se a cultivar BRS Araripe com maior rendimento. A eficiência de uso da água das cultivares de algodoeiro herbáceo foi afetada pelas lâminas de irrigação, decrescendo com o aumento da lâmina de irrigação aplicada, implicando-se dizer que as cultivares estudadas obtiveram um melhor aproveitamento da água quando esta era escassa.

PALAVRAS-CHAVE: Gossypium hirssutum L. r. latifolium H., evapotranspiração, déficit hídrico

\section{YIELD AND WATER USE EFFICIENCY OF COTTON CULTIVARS UNDER IRRIGATION LEVELS DIFFERENT}

ABSTRACT: It was studied the yield and water use efficiency of cotton cultivars under irrigation, in an experiment carried out at the Embrapa Cotton Farm, Barbalha county, CE, Brazil. The experimental design used was a randomized complete block design with four replications, totaling 60 plots arranged in a split block scheme, in a 3 x 5 factorial combination of three cotton cultivars (BRS 286 (C1), BRS Aroeira (C2) and BRS Araripe (C3)) and five irrigation levels (260.93 (L1), 418.93 (L2), 514.21 (L3), 711.81 (L4) and 894.68 (L5)) $\mathrm{mm}$, corresponding to $36,58,72,100$ and $126 \%$ of ETc. The cotton was planted in single

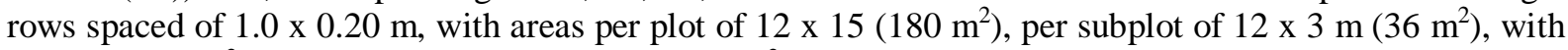
an area of $6 \mathrm{~m}^{2}$, and total experimental of $2160 \mathrm{~m}^{2}$. The volume of water replacement in each irrigation event was based in the second split block (3-6 m of central line sprinkler), called control level, and determined by crop evapotranspiration ( $\left.\mathrm{ET}_{0}\right)$, estimated by Penman-Monteith, multiplied by cotton $\mathrm{Kc}$ in its phases of development $\left(\mathrm{ET}_{\mathrm{C}}=\mathrm{ET}_{0} \mathrm{x} \mathrm{Kc}\right)$. It was observed that the yield of the cultivars were affected by applied irrigation levels and the BRS Araripe e BRS 286, presented rising incomes according increase in

\footnotetext{
${ }^{1}$ Doutorando, UAEAg/CTRN/UFCG. Campina Grande - Paraíba. Email: wpacordao@ hotmail.com.

2 Doutorando, UAEAg/CTRN/UFCG. Pesquisador da Embrapa Algodão. Campina Grande - Paraíba. Email: jose.r.pereira@embrapa.br.

${ }^{3}$ Eng. Agrônoma. Estagiária da Embrapa Algodão. Campina Grande - Paraíba. Email: ericasamara@gmail.com.

4 Doutor, Pesquisador da Embrapa Algodão. Campina Grande - Paraíba. Email: joao-henrique.zonta@embrapa.br; jose.cortez-bezerra@embrapa.br.

${ }^{5}$ Professor da UAEAg/CTRN/UFCG. Campina Grande - Paraíba. Email: Hugo_carvallo@ hotmail.com.
}
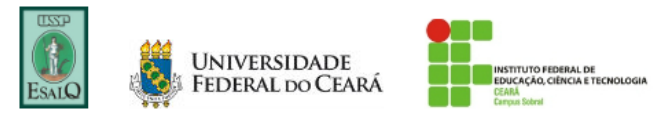
the applied irrigation levels, highlighting the BRS Araripe as the highest yield. Cotton water use efficiency was affected by applied irrigation levels, decreasing with increasing of irrigation, implying saying that the cultivars had one major water use efficiency when water was scarce.

KEYWORDS: Gossypium hirsutum L. r. latifolium H., evapotranspiration, water deficit

\section{INTRODUÇÃO}

Nos últimos anos, o cultivo brasileiro de algodão passou de pequenas áreas com intensa utilização de mão de obra para grandes áreas plantadas e mecanizáveis, principalmente no Centro Oeste e na Bahia e, mais recentemente, no Norte do País. Uma das consequiências dessa expansão é a modernização é a crescente demanda energética da cultura, fato que pouco contempla uma visão ambientalista (BELTRÃO et al., 2011).

Na região Nordeste do Brasil, uma das alternativas será a cultura do algodão (Gossypium hirsutum L. r. latifolium H.), pela grande representatividade tanto do ponto de vista social quanto econômico e pela menor exigência em água, quando comparada com outras espécies (QUEIROZ \& BÜLL, 2001).

O uso da irrigação tem contribuído, significativamente, para o aumento da produção agrícola e para incorporar ao sistema produtivo de áreas cujo potencial é limitado, em função de seus regimes pluviométricos (JÁCOME et al., 2005).

Um dos grandes problemas da região semiárida são as irregularidades pluviométricas que atinge de forma direta e indireta o crescimento e desenvolvimento das culturas, aliadas também, ao manejo incorreto da irrigação.

No entanto, a utilização da irrigação como mecanismo de compensação desses problemas é uma das alternativas para a região, diminuindo os riscos e melhorando a produtividade; mas, até mesmo essa tecnologia encontra grandes adversidades, em decorrência da escassez de água em determinadas regiões, da falta de conhecimento tecnológico por parte dos agricultores e da presença de grandes áreas salinizadas, causando assim uma baixa eficiência dos sistemas de irrigação empregados (FREIRE, 2008).

Dessa forma, a irrigação é o mais importante fator na produção das culturas nessa região, no período seco do ano (DAGDALEN et al., 2006) e uma das práticas que asseguram os níveis de produtividade das culturas (AUJILA et al., 2005). Desse modo, faz-se necessário que os recursos hídricos disponíveis sejam utilizados de maneira racional buscando a maximização da eficiência do uso da água (EUA) (DUARTE et al., 2012).

Diante do exposto, objetivou-se, com o presente trabalho, verificar o rendimento e a eficiência de usa da água de cultivares de algodoeiro herbáceo sob diferentes laminas de irrigação.

\section{MATERIAL E MÉTODOS}

O experimento foi conduzido no Campo Experimental da Embrapa Algodão, no município de Barbalha, CE, localizado nas coordenadas geográficas $7^{\circ} 19^{\prime} \mathrm{S}$ de latitude, $39^{\circ} 18^{\prime} \mathrm{O}$ de longitude e 409,03 m de altitude (RAMOS et al., 2009) a aproximadamente $550 \mathrm{~km}$ da capital do Estado, situada na Mesorregião Sul Cearense e na Microrregião do Cariri Cearense, no período de julho a dezembro de 2010, período compreendido entre o plantio e a colheita (LEDO et al,. 2011).

O clima da região, de acordo com a classificação climática de Köppen adaptada ao Brasil (COELHO \& SONCIN, 1982), é do tipo "CSa", semiúmido, com verão quente e seco (4 a 5 meses) e chuvas de outono e inverno. O período chuvoso é de março a junho e o mais seco é de outubro a dezembro.

O solo da área experimental é do tipo Neossolo Flúvico e sua caracterização química, conforme Boletim No 46/11 do Laboratório de Solos da Embrapa Algodão foi à seguinte: pH de 7,5; 125,$1 ; 78 ; 7,2 ; 6,0$ e 0,0 mmolc $\mathrm{dm}^{-3}$ de cálcio, magnésio, sódio, potássio e alumínio, respectivamente; $24,5 \mathrm{mg} \mathrm{dm}^{-3}$ de fósforo e $18,8 \mathrm{~g} \mathrm{~kg}^{-1}$ de matéria orgânica.

O solo da área experimental foi preparado 15 dias antes do plantio, por meio de arações com arado escarificador a uma profundidade de $20 \mathrm{~cm}$, seguidas de duas gradagens com grade niveladora. 
$\mathrm{Na}$ adubação foram aplicados 90,60 e $20 \mathrm{~kg} \mathrm{ha}^{-1}$ de $\mathrm{N}, \mathrm{P}$ e K, respectivamente, sendo o $\mathrm{N}$ parcelado em três vezes, aplicadas na forma de uréia, com aplicações de 10, 40 e $40 \%$ na adubação de fundação, primeira e segunda adubações de cobertura. $\mathrm{O} \mathrm{N}$ e $\mathrm{P}$ foram aplicados na forma de MAP (fosfato monoamônico) e o K na forma de cloreto de potássio (KCL). Para controle de plantas daninhas, foram feitas três capinas manuais à enxada.

Os tratamentos consistiram da combinação fatorial $3 \times 5$ de três cultivares de algodoeiro herbáceo ((BRS 286 (C1); BRS Aroeira (C2) e BRS Araripe (C3)) e cinco lâminas de irrigação, 260,93 (L1), 418,93 (L2), 514,21 (L3), 711,81 (L4) e 894,68 (L5) mm.

Combinados, os fatores resultaram em 15 tratamentos: (1.L5C1), (2.L5C2), (3.L5C3), (4.L4C1), (5.L4C2), (6.L4C3), (7.L3C1), (8.L3C2), (9.L3C3), (10.L2C1), (11.L2C2), (12.L2C3), (13.L1C1), (14.L1C2) e (15.L1C3), em delineamento em blocos casualizados, com 4 repetições, totalizando 60 subparcelas dispostas em faixas.

As cultivares de algodoeiro herbáceo foram plantadas em fileiras simples com espaçamento de $1,0 \times 0,20 \mathrm{~m}$, tendo a área de cada parcela experimental $12 \times 15 \mathrm{~m}$ perfazendo uma área de $180 \mathrm{~m}^{2}$ por parcela, e área das subparcelas de $12 \times 3 \mathrm{~m}$, com área de $36 \mathrm{~m}^{2}$ e uma área útil (duas fileiras centrais) de $6 \mathrm{~m}^{2}$; portanto, com área total experimental de $2160 \mathrm{~m}^{2}$.

Imediatamente antes do plantio foi efetuada uma irrigação em toda a área de modo a levar o solo à capacidade de campo, e após o plantio, a cada 4 dias uma irrigação com pequena lâmina, de modo a assegurar a boa germinação das sementes. A partir do estabelecimento da cultura, as irrigações foram efetuadas uma vez por semana.

O controle da lâmina de água foi efetuado na segunda faixa (de 3 a $6 \mathrm{~m}$ da linha central) denominada de lâmina de controle, aplicada em função do consumo determinado pela $\mathrm{ET}_{\mathrm{C}}\left(\mathrm{ET}_{0} \mathrm{x} \mathrm{Kc}\right)$, devidamente conferido por pluviômetros instalados em cada subparcela, sendo isso realizado em todos os eventos de irrigação. A primeira faixa ( $0-3 \mathrm{~m}$ a partir da linha central) recebeu uma lâmina maior, e as três últimas (6-9; 9-12 e 12-15 m a partir da linha central), em função da sua localização, receberam lâminas menores que a lâmina de controle. A quantidade de reposição de água $(\mathrm{mm})$ para cada tratamento de irrigação foi determinada de acordo com a evapotranspiração de referência $\left(\mathrm{ET}_{0}\right)$, calculada pelo método de Penman-Monteith (ALLEN et al., 2006), sendo os coeficientes de cultivo conforme Bezerra et al. (2008) com valores de 0,76 (5 a 20 DAP) para a fase I, de 0,95 (21-41 DAP) para a fase II, de 1,09 (42-82 DAP) para a fase III e de 0,88 (83-103 DAP) para a fase IV, respectivamente. Os dados climáticos para uso no cálculo da $\mathrm{ET}_{0}$ foram obtidos da Estação Meteorológica Automática do Instituto Nacional de Meteorologia - INMET de Barbalha, CE.

A água utilizada na irrigação foi de um poço artesiano localizado próximo ao experimento. Antes do início do experimento uma amostra da água foi retirada e levada ao Laboratório de Análises de Solos e Nutrição de Plantas da Embrapa Algodão, para determinações de suas características químicas e classificação, apresentando salinidade média e baixa concentração de sódio podendo ser usada para irrigação sempre que houver um grau moderado de lixiviação e cuidados especiais no manejo do solo.

As lâminas de irrigação aplicadas em cada tratamento ao longo do experimento $(260,93$, $418,93,514,21,711,81$ e 894,68 $\mathrm{mm}$ ) representam respectivamente, 36, 58, 72, 100 e $125 \%$ da evapotranspiração da cultura (ETc).

$\mathrm{Na}$ colheita, foram colhidas e pesadas as duas linhas centrais (área útil) de cada subparcela (6 $\mathrm{m}^{2}$ ), determinando-se a produção por subparcela e seu respectivo rendimento de algodão em caroço por hectare.

A eficiência do uso da água (EUA) foi determinada para cada nível de irrigação através da relação entre a produtividade do algodoeiro herbáceo $\left(\mathrm{kg} \mathrm{ha}^{-1}\right)$ e o consumo de água $\left(\mathrm{m}^{3} \mathrm{ha}^{-1}\right)$ por subparcela durante o ciclo da cultura (DOORENBOS \& KASSAM, 1994; KIJINE et al., 2002).

Os resultados médios foram submetidos à análise de variância e de regressão (lâminas de irrigação), sendo as médias relativas às cultivares comparada pelo teste de Tukey a $5 \%$ de probabilidade através do programa estatístico SISVAR (FERREIRA, 2003). 


\section{RESULTADOS E DISCURSSÃO}

O resumo da análise de variância para as variáveis de produtividade e eficiência de uso da água de irrigação das cultivares de algodoeiro herbáceo (BRS 286, BRS Aroeira e BRS Araripe), submetidas a diferentes lâminas de irrigação, é apresentado nas Tabelas 1, respectivamente.

Houve efeito significativo das cultivares apenas na variável produtividade das cultivares de algodoeiro herbáceo estudadas. Em relação ao fator lâminas, observa-se que ambas as variáveis foram afetadas. Apenas para a variável produtividade, houve interação entre as lâminas de irrigação e as cultivares de algodoeiro herbáceo estudado (Tabela 1), significando que o efeito da lâmina de água testada para todas as variáveis analisadas pode ser diferente para cada cultivar estudada. Como também, que as cultivares reagiu de forma diferente à aplicação das diferentes lâminas de irrigação.

Na Figura 1 apresentam-se as tendências polinomiais apresentadas pela variável produtividade para cada uma das três cultivares de algodoeiro herbáceo dentro de todas as lâminas de irrigação aplicadas. De acordo com o modelo matemático, a produtividade foi afetada quadraticamente pelas lâminas aplicadas em todos as cultivares (BRS 286, BRS Aroeira e BRS Araripe). Pode-se dizer que as produtividades das cultivares BRS 286, BRS Aroeira e BRS Araripe foram crescentes com o aumento da lâmina de irrigação aplicada, com lâminas máximas calculadas de 766,4, 631 e 734,7 mm, para produtividade máxima calculada de, 5321,82; 4197,07 e 5722,75 kg ha-1 (valores calculados com base nas equações 1,2 e 3), com acréscimo entre a lâmina mínima aplicada (L1 - 260,93mm) e a lâmina máxima calculada de $152,9,40,39$ e $100,41 \%$, respectivamente, decaindo um pouco a partir destes pontos.

No histograma (Figura 2) é apresentado o comportamento da produtividade das 3 cultivares utilizados dentro de cada lâmina de irrigação aplicada, bem como o de cada uma delas nas diferentes lâminas de água aplicadas. Para cada lâmina aplicada as cultivares apresentaram diferentes comportamentos produtivos, mas nas quatro maiores lâminas de irrigação aplicadas (L2 - 418,93, L3 514,21, L4 - 711,81 e L5 - 894,68 mm) destaca-se a cultivar BRS Araripe.

Salienta-se que a produtividade do algodoeiro obtido para as cultivares BRS 286, BRS Aroeira e BRS Araripe (5181,9; 4248,03 e 5644,71 $\mathrm{kg} \mathrm{ha}^{-1}$, respectivamente) ficaram todos acima das suas características varietais $\left(4874,3841\right.$ e $4679 \mathrm{~kg} \mathrm{ha}^{-1}$, respectivamente), conforme Silva Filho et al. (2009), Freire et al. (2009) e Vidal Neto et al. (2006). No geral, observa-se que a produtividade do algodão para cada cultivar variou com a lâmina de irrigação aplicada, aumentando proporcionalmente, exceto na BRS Aroeira que diminuiu a partir da lâmina 514,21 (L3) $\mathrm{mm}$ e que pelos resultados obtidos, a cultivar BRS Aroeira e mais tolerante ao déficit hídrico e a cultivar BRS 286 é mais susceptível ao excesso hídrico presente no solo, necessitando de repetição do ensaio para confirmação do mesmo.

Sousa Júnior et al. (2005) e Cordão Sobrinho et al. (2007) reportaram que baixos níveis de água no solo ocasionaram redução na produtividade do algodão. Como também, o excesso de água no solo pode influenciar negativamente o desenvolvimento das culturas, pois segundo Beltrão et al. (2011) a anoxia causa modificações profundas no metabolismo da planta, o que afeta de maneira geral o crescimento, desenvolvimento e a produtividade das plantas.

A adequada disponibilidade hídrica proporcionou aumento de produtividade e obtenção de fibra de melhor qualidade. Por outro lado, a deficiência hídrica diminui a resistência e a finura da fibra, o diâmetro do caule, a altura de planta e, consequientemente, a produtividade (NUNES FILHO et al., 1998, CORDÃO SOBRINHO et al., 2007).

A curva de regressão para a variável eficiência de uso da água versus lâminas de irrigação está apresentada na Figura 3. A eficiência de uso da água diminuiu proporcionalmente de acordo com o aumento da lâmina de irrigação aplicada, ou seja, quanto maior a lâmina de irrigação aplicada menor a eficiência de uso da água. O maior e menor valor de EUA foram de 1,65 e 0,54 $\mathrm{kg} \mathrm{m}^{-3}$, encontrados nas lâminas mínima e máxima aplicadas, iguais a 260,93 (L1) e 894,68 (L5) mm, respectivamente (Figura 2). No entanto, este fato não implica dizer que as mais altas produtividades foram encontrados pelos mais altos valores de eficiência de uso da água, e sim que as cultivares estudadas responderam mais satisfatoriamente ao déficit hídrico.

Trabalhos realizados por Singh et al. (2010) encontraram resultados semelhantes aos aqui apresentados, trabalhando com irrigação com déficit na região semiárida. Os autores encontraram efeito significativo na EUA para as diferentes lâminas de irrigação estudadas, com valores variando de 
0,54 a 0,64 $\mathrm{kg} \mathrm{m}^{-3}$, para as lâminas de $100 \%$ ETc e $50 \%$ ETc, respectivamente, valores muito próximos aos aqui encontrados. Outros autores como Dagdelen et al. (2009) também observaram uma maior EUA através da irrigação com déficit, sendo que a EUA com a lâmina de $25 \%$ da ETc foi igual a $1,46 \mathrm{~kg} \mathrm{~m}^{-3}$, enquanto que na irrigação com $100 \%$ da ETc a EUA foi de $0,81 \mathrm{~kg} \mathrm{~m}^{-3}$.

\section{CONCLUSÕES}

A produtividade e a eficiência de uso da água das cultivares de algodoeiro herbáceo foram afetadas pelas lâminas de irrigação. As maiores produtividades das cultivares foram verificadas ao se aplicar lâminas entre 600 e $800 \mathrm{~mm}$ e, quanto à eficiência de usa da água, seus valores foram menos eficientes, com o aumento da lâmina de irrigação aplicada.

\section{REFERÊNCIAS BIBLIOGRÁFICAS}

ALLEN, R. G.; PRUIT, W. O.; WRIGHT, J. L.; HOWELL, T. A.; VENTURA, F.; SNYDER, R.; ITENFISU, D.; STEDUTO, P.; BERENGENA, J.; YRISARRY, J. B.; SMITH, M.; PEREIRA, L. S.; RAES, D.; PERRIER, A.; ALVES, I.; WALTER, I.; ELLIOTT, R. A recommendation on standardized surface resistance for hourly calculation of reference ETo by the FAO56 PenmanMonteith method. Agricultural Water Management, Amsterdam, v. 81, p. 1-22, 2006. http://dx.doi.org/10.1016/j.agwat.2005.03.007

AUJILA, M. S.; THIND, H. S.; BUTTAR, G. S. Cotton yield and water use efficiency at various levels of water and $\mathrm{N}$ through drip irrigation under two methods of planting. Agricultural Water Management, v. 71, p.167- 179, 2005. http://dx.doi.org/10.1016/j.agwat.2004.06.010

BELTRÃO, N. E. de M.; OLIVEIRA, M. I. P. de; SOUSA JÚNIOR, S. P. de; BRITO, G. G. de; CARDOSO, G. D. Ecofisiologia do algodoeiro (Gossypium hirsutum L. r. latifolium Hutch.). In: BELTRÃO, N. E. de M.; OLIVEIRA, M. I. P. de. Ecofisiologia das culturas de algodão, amendoim, gergelim, mamona, pinhão-manso e sisal. Brasília, DF: Embrapa Informação tecnológica, 2011. 1 ed, Cap. 2, p. 65-124.

BEZERRA, J. R. C.; LUZ, M. J. da S. e.; BARRETO, A. N.; AMORIM NETO, M. da S.; SILVA, L. C. Irrigação do algodoeiro herbáceo. In: BELTRÃ̃, N. E. de M.; AZEVEDO, D. M. P. de. O agronegócio do algodão no Brasil. Brasília: Embrapa Informação Tecnológica, 2008. v.2, Cap.27, p. 875-950.

COELHO, M. A.; SONCIN, N. B. Geografia do Brasil. São Paulo: Moderna. 1982. 368 p.

CORDÃO SOBRINHO, F. P.; FERNANDES, P. D.; BELTRÃO, N. E. M.; SOARES, F. A. L.; TERCEIRO NETO, C. P. C. Crescimento e rendimento do algodoeiro BRS - 200 com aplicações de cloreto de mepiquat e lâminas de irrigação. Revista Brasileira de Engenharia Agrícola e Ambiental, Campina Grande, v. 11, n. 3, p. 284-292, 2007.

DAGDELEN, N.; BASAL, H.; YILMAZ, E.; GURBZ, T.; AKCAY, S. Different drip irrigation regimes affect cotton yield, water use efficiency and fiber quality in western Turkey. Agricultural Water Management, v.96, n.1, p.111-120, 2009. http://dx.doi.org/10.1016/j.agwat.2008.07.003

DAGDELEN, N.; YILMAZ, E.; SEZGIN, F.; GÜRBÜZ, T. Water-yield relation and water use efficiency of cotton (Gossypium hirsutum L.) and second crop (Zea mays L) in western Turkey. Agricultural Water Management, v. 82, p.63-85, 2006.

DOORENBOS, J.; KASSAM, A. H. Efeito da água no rendimento das culturas. Campina Grande: UFPB, 1994. 306 p. (Estudos FAO: Irrigação e Drenagem, 33).

DUARTE, J. M. de L.; LIMA, A. D.; NASCIMENTO, R. S.; VIANA, T. V. de A.; SARAIVA, K. R.; AZEVEDO, B. M. de. Eficiência do uso da água na produção de óleo do girassol (helliantus annuus L.), sob suspensão hídrica. Revista Brasileira de Agricultura Irrigada, v.6, n. 3, p. 166 175, 2012. http://dx.doi.org/10.7127/rbai.v6n300081

FERREIRA, D. F. Sisvar. Lavras: DEX/UFLA, versão 5.0 (Build 67), 1999-2003.

FREIRE, E. C.; BELTRÃO, N. E. de M.; VALE, D. G. BRS Aroeira. Campina Grande: Embrapa Algodão, 2009. 2 p. 1 Folder.

FREIRE, S. A. B. Efeito da lâmina de irrigação no crescimento e na produção do algodão herbáceo irrigado por gotejamento, no semi-árido do Rio Grande do Norte. 2008. 51 p. Dissertação 
(Mestrado em Irrigação e Drenagem - Área de concentração Manejo da Irrigação) - Universidade Federal Rural do Semi-Árido. Mossoró, RN.

JÁCOME, A. G.; FERNANDES, P. D.; GHEYI, H. G.; GONÇALVES, A. C. A.; SILVA, F. F. da. Avaliação de genótipos de algodoeiro sob níveis de salinidade da água de irrigação. Revista Brasileira de Engenharia Agrícola e Ambiental, Campina Grande, Suplemento, p.365-369, 2005.

KIJINE, J. W.; TUONG, T. P.; BENNETT, J.; BOUMAN, B.; OWEIS, T. Ensuring food security via improvement in crop water productivity. Challenge Programme on Water and Food, Back ground Paper 1, 2002.

LEDO, E. R. F.; SILVA, M. G. da; NOGUEIRA, D. H.; MIRANDA, E. P. de; ARAÚJO, E. M.; ARAÚJO, E. M. Avaliação de metodologias empregadas no cálculo da temperatura média diária do ar na região de Barbalha-CE. Revista Brasileira de Agricultura Irrigada, v.5, n.4, p.310 - 319, Fortaleza, CE, 2011.

NUNES FILHO, J.; SÁ, V. A .L.; OLIVEIRA JÚNIOR, I. S.; COUTINHO, J. L. B.; SANTOS, V. F. Efeito de lâminas de irrigação sobre o rendimento e qualidade da fibra de cultivares de algodoeiro herbáceo (Gossypium hirsutum L. r. latifolium Hutch). Revista Brasileira de Engenharia Agrícola e Ambiental, Campina Grande, v.2, n.3, p.295-299, 1998.

QUEIROZ, S. O. P. de.; BÜLL, L. T. Comportamento de genótipos de algodão herbáceo em função da salinidade do solo. Irriga, Botucatu, v.6, n.2, p.124-134, 2001.

ROSOLEM, C. A. Produtividade máxima da soja. Rondonópolis: Fundação MT, 2007. p. 237-244. (Boletim de Pesquisa de Soja).

RAMOS, A. M.; SANTOS, L. A. R. dos; FORTES, L. T. G (Orgs.) Normas climatológicas do Brasil: 1961-1990. Brasília: INMET, 2009. 465p.

SILVA FILHO, J. L da; PEDROSA, M. B.; MORELLO, C. de L.; FREIRE, E. C.; ALENCAR, A. R. de; ANDRADE, F. P. de; CHITARRA, L. G.; FARIAS, F. J. de C.; VIDAL NETO, F. das C. BRS 286. Campina Grande: Embrapa Algodão, 2009, 2 p. 1 Folder.

SINGH, Y.; RAO, S. S.; REGAR, P. L. Deficit irrigation and nitrogen effects on seed cotton yield, water productivity and yield response factor in shallow soils of semi-arid environment. Agricultural Water Management, v.97, p.965-970, 2010. http://dx.doi.org/10.1016/j.agwat.2010.01.028

SOUSA JÚNIOR, S. P. de; SOARES, F. A. L.; SIQUEIRA, E. da C.; GHEYI, H. R.; FERMANDES, P. D.; BELTRÃO, N. E. de M. Germinação, crescimento e produção do algodoeiro colorido BRS Verde sob estresse salino. Revista Brasileira de Engenharia Agrícola e Ambiental, Campina Grande, v.9, p. 236-241, 2005. Suplemento.

VIDAL NETO, F. das C.; FREIRE, E. C.; ANDRADE, F. P. de; FONSECA, R. G. da; SANTOS, J. W. dos; ARAÚJO, G. P. de; ASSUNÇÃO, J. H. de; LUCENA, M. do C. L.; GUIMARÃES, G. L. BRS Araripe. Campina Grande: Embrapa Algodão, 2006, 2 p. 1 Folder.

Tabela 1. Resumo da análise de variância para as variáveis produtividade (PROD_kg ha-1) e eficiência de uso da água de irrigação_EUA $\left(\mathrm{Kg} \mathrm{m}^{-3}\right)$ das cultivares de algodoeiro herbáceo submetidas a diferentes lâminas de irrigação, Barbalha, CE, 2010 .

\begin{tabular}{lccc}
\hline FV & GL & PROD & EUA \\
\hline Bloco & 3 & 3265923,5 & 0,124967 \\
\hline Cultivar (C) & 2 & $4855404,1^{* *}$ & $0,111422^{\text {ns }}$ \\
Erro 1 & 6 & 293027,7 & 0,0422248 \\
\hline Lâminas (L) & 4 & $10778776,8^{* *}$ & $2,250914^{* *}$ \\
Erro 2 & 12 & 276043,9 & 0,057082 \\
\hline (C x L) & 8 & $1341156,6^{* *}$ & $0,029797^{\text {ns }}$ \\
Erro 3 & 24 & 248729,46 & 0,020018 \\
\hline Total & 59 & & 1,0043333 \\
\hline Média Geral & \multicolumn{4}{|}{4238,92} \\
\hline CV 1 (\%) & - & 12,77 & 23,79 \\
CV 2 (\%) & - & 12,39 & 14,09 \\
CV 3 (\%) & - & 11,77 &
\end{tabular}




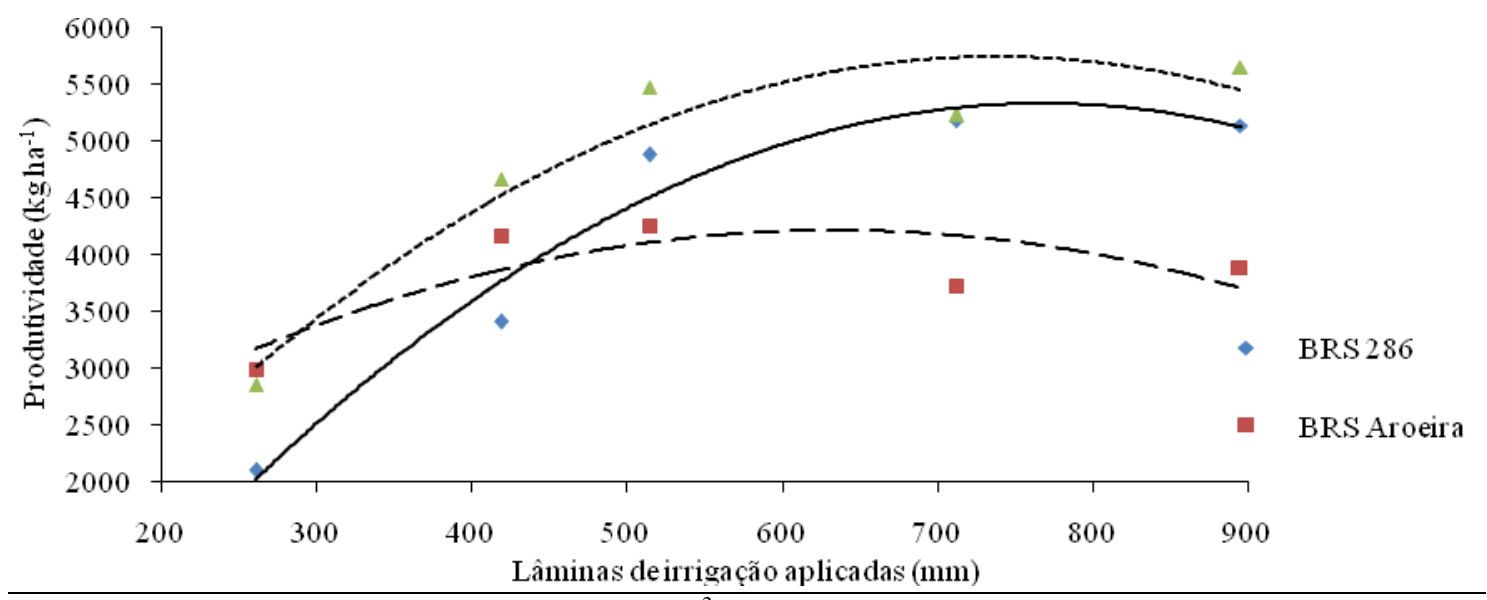

BRS $286(* *)=y\left(2^{\circ}\right.$ grau $)=-0,0129 x^{2}+19,774 \mathrm{x}-2255,9, \mathrm{R}^{2}=0,9607$, Equação 1

BRS Aroeira $(* *)=y\left(2^{\circ}\right.$ grau $)=-0,0075 x^{2}+9,4651 x+1210,8, R^{2}=0,6325$, Equação 2

BRS Araripe $(* *)=y\left(2^{\circ}\right.$ grau $)=-0,0121 x^{2}+17,781 x-809,59, R^{2}=0,9133$, Equação 3

Figura 1. Produtividade das três cultivares de algodoeiro herbáceo em função das lâminas de irrigação estudadas, Barbalha, CE, 2010.

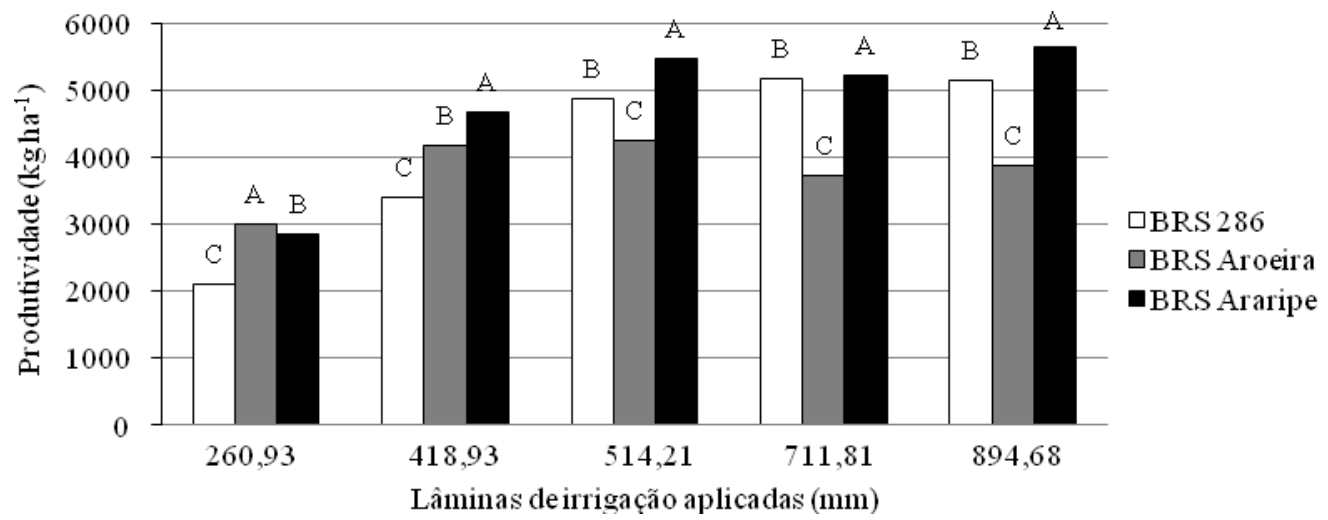

Figura 2. Produtividade das cultivares de algodoeiro herbáceo avaliados em função de cada lâmina de irrigação aplicada, Barbalha, CE, 2010.

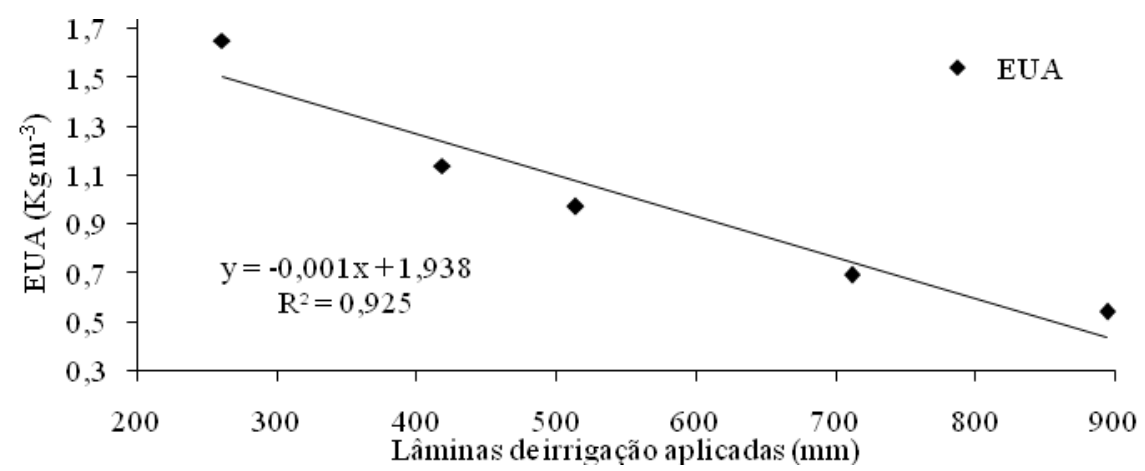

Figura 3. Eficiência de uso da água do algodoeiro herbáceo em função das lâminas de irrigação estudadas, Barbalha, CE, 2010. 